\title{
Matérián
}

Revista Matéria, v. 12, n. 1, pp. 173 - 178, 2007

ISSN 1517-7076

http://www.materia.coppe.ufrj.br/sarra/artigos/artigo10865

\section{Controle de Força de Preensão para uma Órtese de mão por meio da Análise da Corrente Elétrica do Atuador}

\author{
Daniel N. Rocha ${ }^{1}$, Kátia V. Meneses ${ }^{1}$, Adriano A. Afonso ${ }^{1}$, Mauricio F. S. Corrêa ${ }^{1}$, \\ Carlos E. P. Batista ${ }^{1}$, Marcos Pinotti ${ }^{2}$ \\ ${ }^{1}$ Programa de Pós-Graduação em Engenharia Mecânica, Universidade Federal de Minas Gerais, \\ DEMEC/UFMG, CEP 31270-901, Belo Horizonte, M. G., Brasil \\ e-mail: danielnr@pop.com.br; kvpm@uai.com.br; adrianoamancio@yahoo.com.br \\ e-mail:mauferrari@yahoo.com.br; kadu_mec@yahoo.com.br \\ ${ }^{2}$ Departamento de Engenharia Mecânica, UFMG \\ e-mail: pinotti@demec.ufmg.br
}

\section{RESUMO}

Visando fazer o controle da força de preensão de uma órtese de mão, foi desenvolvido um circuito eletrônico que usa como feedback a corrente elétrica do atuador, um motor de corrente contínua. Verificando-se a ocorrência da sobre-corrente no atuador este é desativado. Essa sobre-corrente é ajustada de acordo com a força de preensão desejada. Experimentos realizados determinaram a força no tendão artificial e conseqüentemente o torque. Como resultado, foi obtido o controle da força de preensão de acordo com uma regulagem no circuito eletrônico. Este trabalho possibilitará maior segurança do usuário e controle do equipamento.

Palavras chaves: Controle, força, preensão, órtese, atuador.

\section{Grip Force Control for a Hand's Orthosis by the Analysis of the Actuator Electric Currente}

\begin{abstract}
Planning to make the hold force control of one hand's orthosis, an electronic circuit was developed using the actuator electric current (direct-current motor) as feedback. Verifying the occurrence of over currente in the actuator, it is disactivated. This over chain is regulated in accordance with grip force desired. Carried through experiments the force in the artificial tendons was determined and consequently the torque. As result, the grip force control was gotten in accordance with a regulation in the electronic circuit. This work makes possible greater security for the user and equipment's control.
\end{abstract}

Keywords: Control, force, grip, orthosis, actuator.

\section{INTRODUÇÃO}

A história da medicina demonstra que as órteses já eram utilizadas desde a antiguidade, porém aplicadas sem princípios e técnicas definidas e construídas de maneira artesanal e sem interesse pelos aspectos estéticos. Nos últimos anos houve um avanço nesta área da reabilitação, com a utilização de materiais mais leves e com técnicas mais sofisticadas que possibilitam melhores resultados funcionais [1, 2]. Mesmo com os avanços tecnológicos, as órteses disponíveis atualmente apresentam várias desvantagens. Estas são freqüentemente desajeitadas, pouco aceitáveis esteticamente, fornecem pouca função, além do difícil acesso dos pacientes a estes equipamentos que em geral são de altíssimo custo e complexos em termos de mecânica e controle [3, 4]. Diante da necessidade de construção de equipamentos mais eficazes, com menor custo e com melhores resultados funcionais, foi desenvolvida, no Laboratório de Bioengenharia da UFMG (Labbio-UFMG), uma órtese funcional para mão. 


\section{1 Órtese}

A órtese de mão (Figura 1) é composta por uma luva, modificada, de proteção que envolve a mão do usuário, um circuito elétrico, sensores de superfície e tendões artificiais (Figura 2). Estes irão reproduzir a função dos tendões da mão humana, transmitindo o movimento do atuador eletromecânico, para a mão, promovendo os movimentos de flexão e extensão das articulações metacarpofalangeanas (MCF) e interfalangeanas (IF) dos dedos $2^{\circ}$ ao $5^{\circ}$, de forma a se adaptar a objetos de diferentes formas e tamanhos. $\mathrm{O}$ acionamento da órtese é realizado pelo próprio usuário através de sinais mioelétricos de músculos preservados.

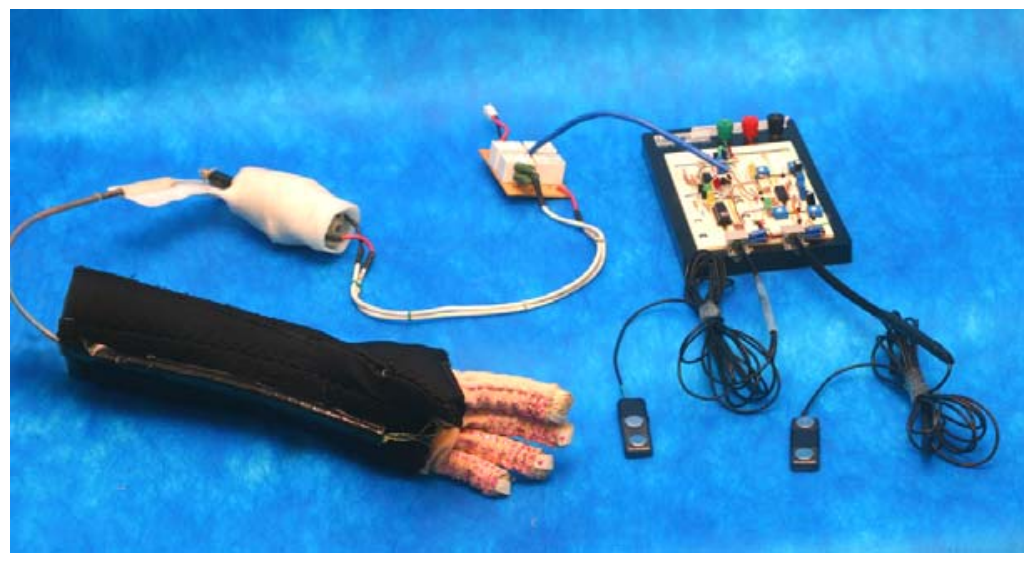

Figura 1: Órtese funcional para mão desenvolvida no Laboratório de Bioengenharia da UFMG.

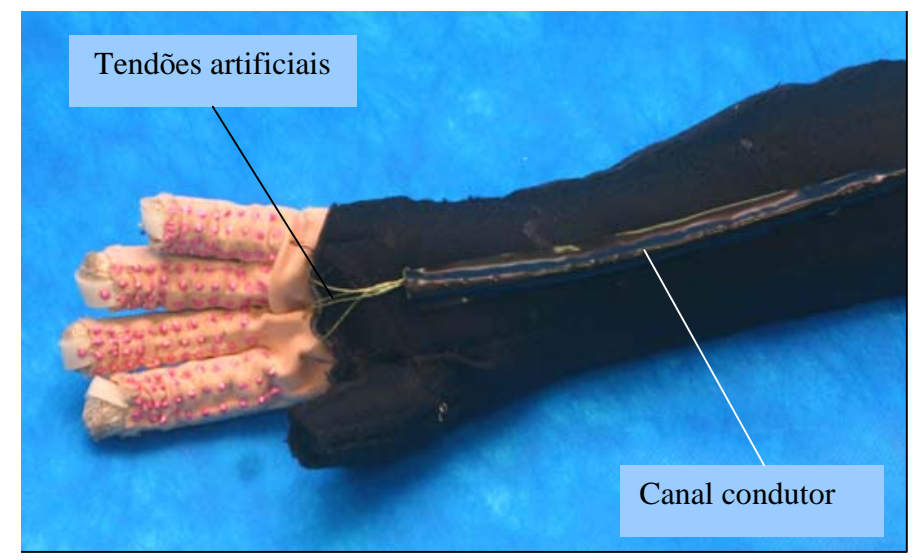

Figura 2: Tendões artificiais da órtese de mão desenvolvida no Labbio-UFMG

Para a construção de uma órtese de mão segura é necessário à verificação e limitação da força de preensão da órtese, pois sua principal função é auxiliar as atividades do cotidiano do paciente, tanto para preensão de objetos como para contato com pessoas.

\subsection{Atuador: Motor de corrente contínua (CC).}

Um motor CC foi utilizado como atuador da órtese de mão. Um motor elétrico é composto basicamente por um rotor, um estator e comutador.

O estator gera um campo magnético fixo, enquanto no rotor a corrente elétrica que gera o campo magnético é alternada pelo comutador. A corrente elétrica (i) ao passar pela bobina entre os pontos A-C e DE, interage com o campo magnético B gerando a força $F$ (Figura 3). A força gerada resulta no torque no motor CC. 


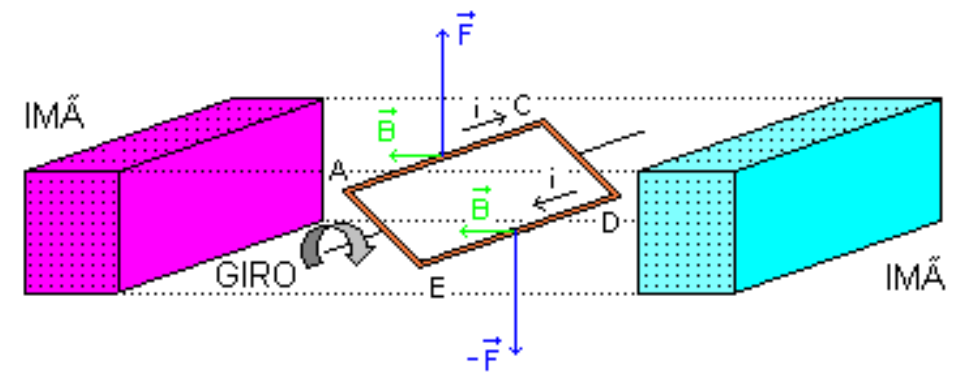

Figura 3: Força gerada pela interação dos campos.

\section{OBJETIVO}

O objetivo deste trabalho foi desenvolver um sistema para controlar a força máxima da órtese durante a preensão de objetos.

\section{METODOLOGIA}

Neste trabalho foi desenvolvido um sistema de ativação e controle para uma órtese de mão do laboratório de Bioengenharia da UFMG.

O sistema de ativação e controle é responsável pelo monitoramento em tempo real da órtese, assim garantindo uma maior segurança para o usuário.

Inicialmente será necessária a determinação da força de tração no tendão artificial ao segurar massas de até $1 \mathrm{Kg}$, pois esta tração está diretamente relacionada com a força de preensão dos dedos da órtese. Determinado a força de tração será feito um circuito eletrônico de segurança, este irá analisar em tempo real o atuador, fazendo um controle seguro para a preensão da órtese.

\subsection{Determinação da Força de Tração no Tendão Artificial}

Foi medida a força de tração nos tendões ventrais da órtese em função do ângulo de flexão da articulação metacarpofalangiana. A órtese foi fixada em uma bancada de testes com cabos presos na ponta dos dedos $\left(2^{\circ}\right.$ ao $\left.5^{\circ}\right)$ conforme mostrado na Figura 4. Em sua extremidade foi aplicada uma força controlada. Um dinamômetro foi fixado aos tendões ventrais da órtese. Forças de 100gf até uma carga máxima de 1000gf foram aplicadas. A cada variação de 100gf aplicado na extremidade do cabo se mediu a reação nos tendões da órtese. Este procedimento foi realizado para os ângulos de $30^{\circ}, 60^{\circ}$ e $90^{\circ}$ durante a flexão dos dedos da órtese e para os ângulos de $60^{\circ}$ e $30^{\circ}$ durante a extensão. Quando se completou a carga máxima (1000g), o peso era retirado (100g) progressivamente (Figura 4).
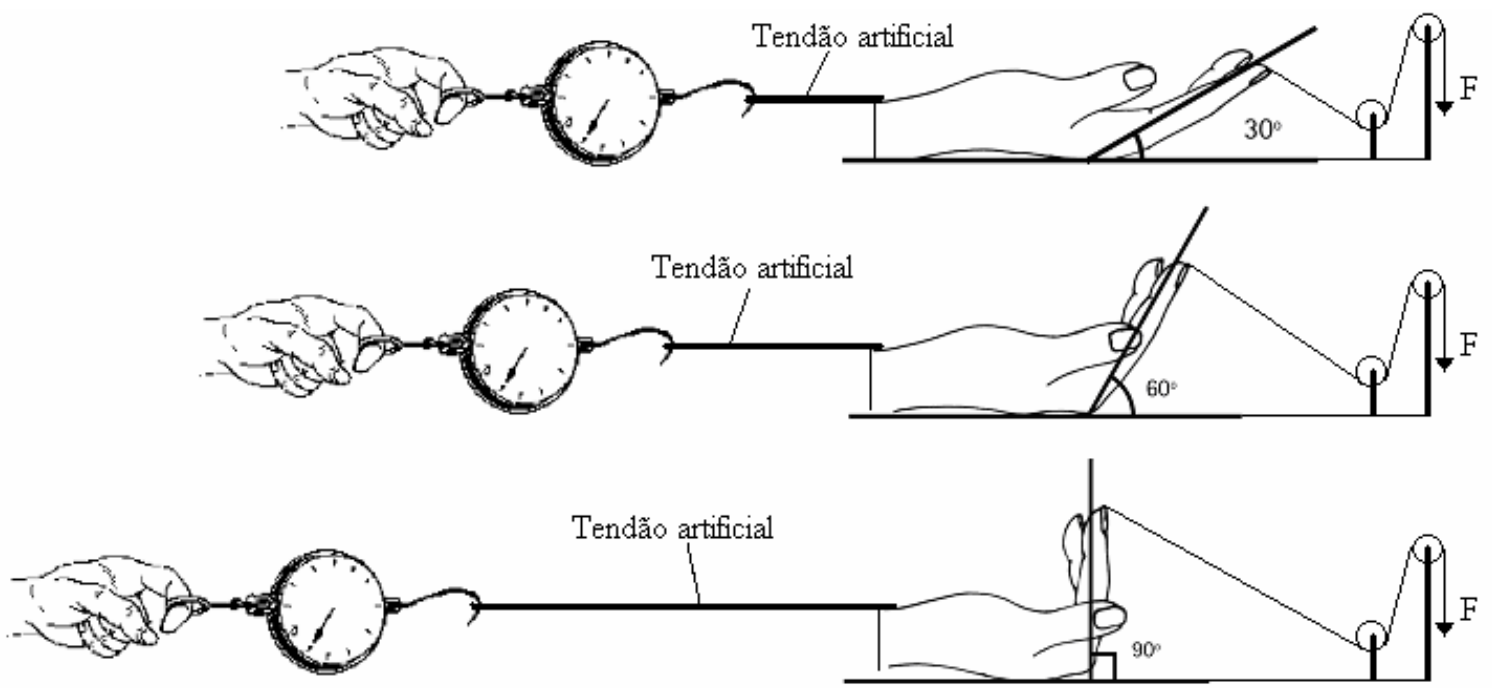

Figura 4: Experimento para determinação da tração no tendão artificial 


\subsection{Controle de Torque}

A intensidade da corrente que flui na bobina é responsável pela intensidade do campo magnético e conseqüentemente pelo torque do motor.

Com um aumento de carga no eixo do motor, gera-se um aumento no torque. Isto exige um aumento no consumo de potência e assim gerando um aumento da corrente elétrica. elétrica.

Assim pode-se verificar o aumento do torque em função do aumento da intensidade da corrente

A Figura 5 mostra o aumento da corrente, curva I, em função do aumento do torque, assim ao determinar o torque necessário para preensão poderá determinar a corrente correspondente.

A partir da análise da corrente elétrica pode-se controlar a força de preensão da órtese de mão.

Usando o gráfico de especificações de um motor CC da fabricante Johnson Eletric, pode-se levantar as informações necessárias. O Gáfico 1 possui as curvas $\mathrm{N}$ de rotação(rpm), Eff de eficiência(\%), P de potencia(Watt) e I de corrente(amp) em função do torque(m-Nm).

РT03002

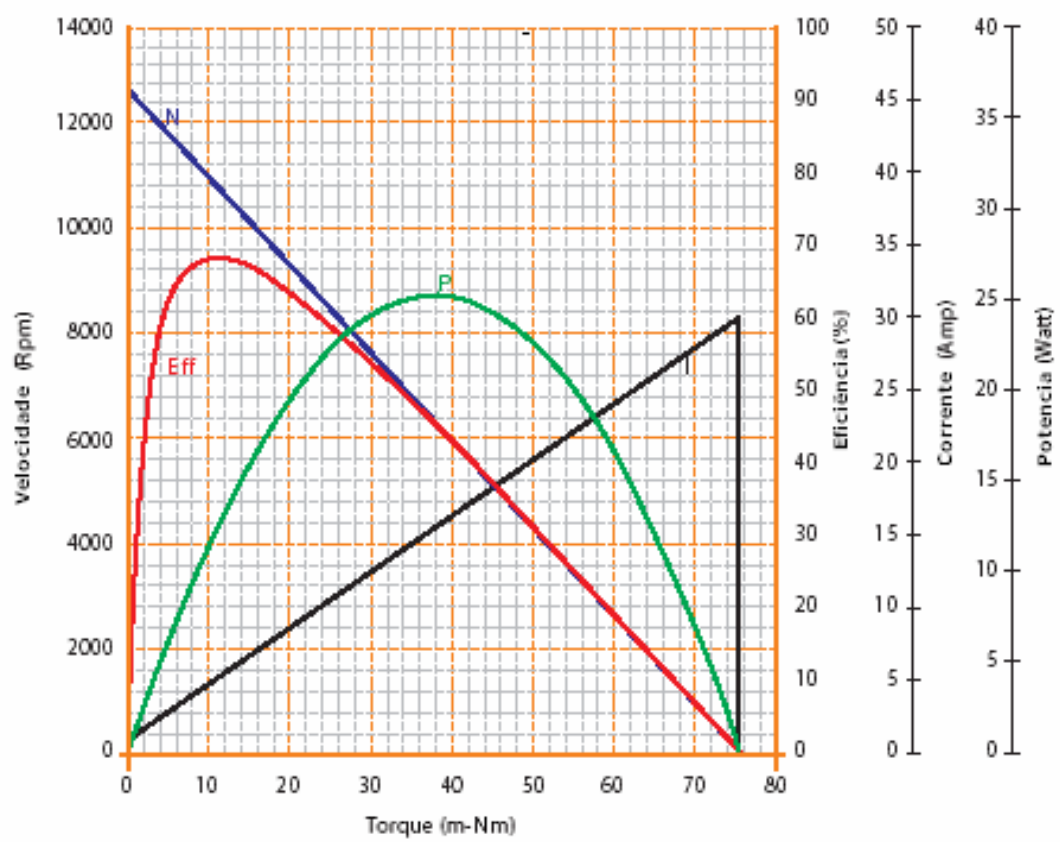

Figura 5: Desempenho do motor. Fonte: Johnson Eletric, 2005.

O acionamento do motor CC é feito por um circuito de controle, esse circuito contém alimentação, entrada para sensores mioelétricos, entrada de sinal do circuito de análise e saída para a ponte H. O circuito de controle é constituído por um micro-controlador, este recebe os sinais dos sensores mioelétricos e do circuito de análise, por uma lógica de funcionamento e de segurança ocorre o acionamento da ponte $\mathrm{H}$.

A ponte $\mathrm{H}$ consiste em um conjunto de reles. Dependendo do chaveamento dos reles será aplicar diretamente a tensão de entrada na saída ou pode-se inverter a tensão de entrada na saída. Pelo fato do motor de corrente contínua girar de acordo com a polarização de sua alimentação é necessário o uso da ponte $\mathrm{H}$ para poder inverter o sentido de rotação do motor.

Um circuito de análise foi criado, este fica em série com a alimentação do motor. A mesma corrente elétrica que passa pelo motor passa pelo circuito de análise, o circuito de análise verifica a intensidade da corrente elétrica, assim funcionando como "feedback" ele envia informação para o circuito de controle. A intensidade máxima de corrente é pré-determinada de acordo com o torque desejado. Quando identificado esse valor de corrente, o circuito de análise envia um sinal para o circuito de controle que desliga a alimentação do motor CC (Figura 6). 


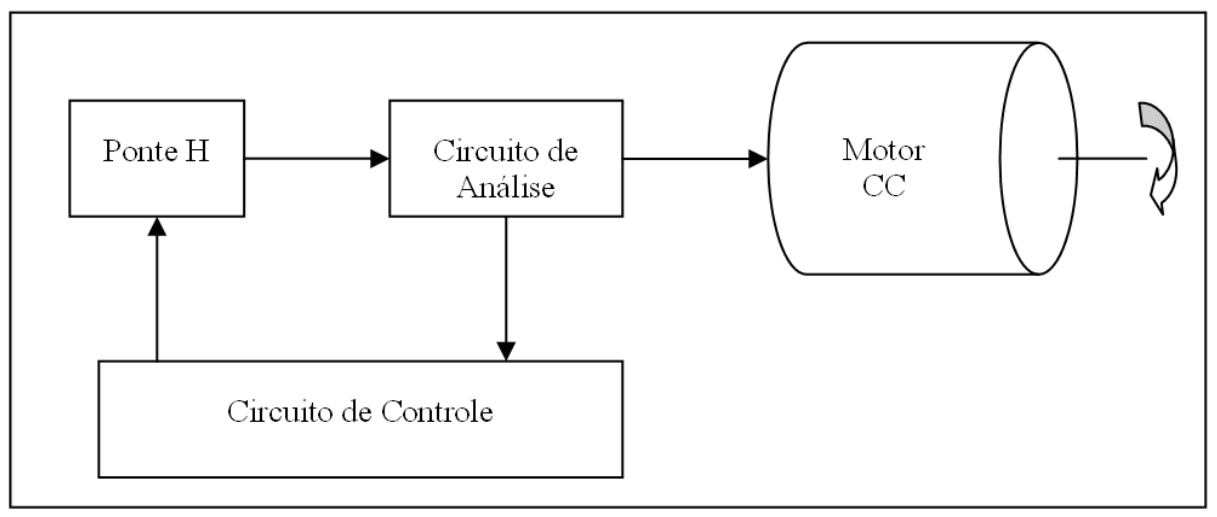

Figura 6: Diagrama de blocos do Circuito completo da órtese.

\section{RESULTADOS E DISCUSSÃO}

A partir do experimento realizado, foi traçado o gráfico da Figura 7, que mostra as curvas de tração do tendão da órtese ao realizar diferentes movimentos, com as massas selecionadas.

Podemos verificar o aumento da tração de acordo com o aumento do ângulo de fechamento. Assim podemos determinar a maior força de tração no tendão para o ângulo de $90^{\circ}$. A tração máxima no experimento para a maior carga foi próxima de $45 \mathrm{~N}$, por meio de segurança a tração será arredondada para $45 \mathrm{~N}$.

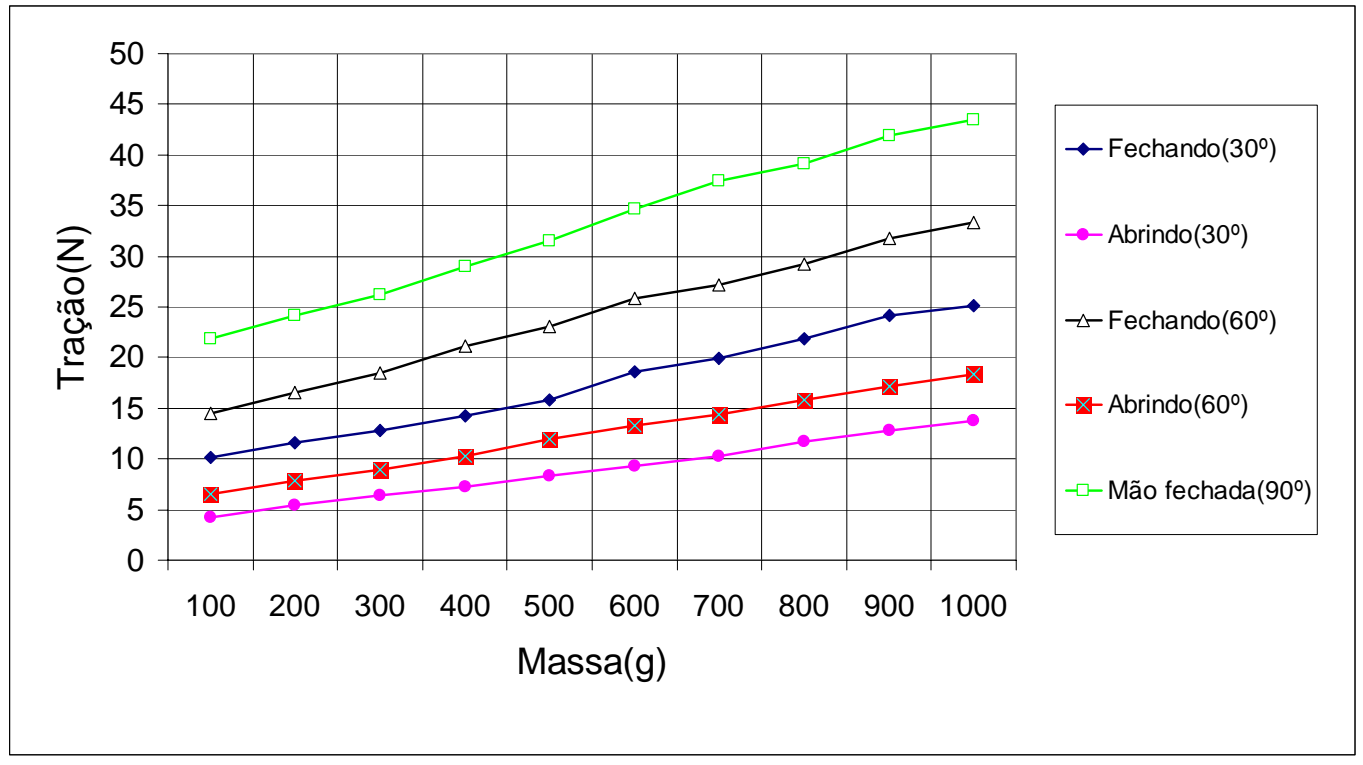

Figura 7: Tração no tendão da órtese versus massa sustentada.

Após determinação da força de tração no tendão artificial necessária para a preensão de objetos, serão usadas as informações do fabricante de motor para determinar a corrente elétrica para este torque.

Foi criado um controle de preensão da órtese de mão usando um circuito de análise da corrente elétrica do atuador, assim tornando a órtese segura para o seu uso diário.

Existem sensores para medir pressão que podem ser adaptados na órtese a fim de medir a força de preensão. Por ser uma órtese a fixação destes resultaria em um aumento na estrutura da luva.

O circuito de análise tem seu custo muito baixo em comparação aos sensores atuais utilizados assim viabilizando sua implementação.

\section{AGRADECIMENTOS}

Autores gostariam de reconhecer o apoio financeiro de CNPq e CAPES. 


\section{BIBLIOGRAFIA}

[1] FESS, E.E., “A History of Splinting: to Understand the Present, View the Past”, Journal of Hand Therapy, pp. 97-132, apr.-jun. 2002.

[2] LIANZA, S., Medicina de Reabilitação, ed. 3, Guanabara Koogan, 2001.

[3] PETROFF, N. et al., "Fuzzy-control of a Hand Orthosis for Restoring Tip Pinch, Lateral Pinch, and Cylindrical Prehensions to Patients with Elbow Flexion Intact”, IEEE Transactions on Neural Systems and Rehabilitation Engineering, v. 9, n. 2, pp. 225-231, jun. 2001.

[4] ROMILLY, D.P., et al., "A Functional task: Analysis and Motion Simulation for the Development of a Powered upper-limb Orthosis", IEEE Transactions on Rehabilitation Engeneering, v. 2, n. 3, pp. 119-129, sep 1994. 